\title{
Lack of Association of a Functional Polymorphism in the Interleukin 8 Gene with Susceptibility to Periodontitis
}

\author{
Yeon J. Kim, ${ }^{1}$ Aline C. Viana, ${ }^{1}$ Karen M.C. Curtis, ${ }^{2}$ Silvana R.P. Orrico, ${ }^{1}$ \\ Joni A. Cirelli, ${ }^{1}$ and Raquel M. Scarel-Caminaga ${ }^{2}$
}

The important inflammatory mediator interleukin-8 (IL-8) is responsible for the migration and activation of neutrophils. The IL8 gene contains a functional single-nucleotide polymorphism (SNP) (rs4073) in its promoter region that may influence the expression of IL-8, and which has been associated with inflammatory diseases. The purpose of this study was to investigate the association of the SNP (rs4073) in the IL8 gene with susceptibility to periodontitis. DNA was extracted from the buccal epithelial cells of 500 individuals (control $n=224$ and periodontitis $n=276$ ). Individuals were genotyped for the SNP (rs4073) using sequence-specific primer polymerase chain reaction. Associations between the SNP (rs4073) and subject phenotypes were analyzed using the chisquared test, followed by univariate and multivariate logistic regression modeling. The genotype distributions in both groups were consistent with Hardy-Weinberg equilibrium. Univariate and multivariate analysis showed that age, skin color, and smoking status were associated with periodontitis. No significant differences were found for sex and frequencies of alleles and genotypes between the control and periodontitis groups in the univariate analysis. These findings were replicated in the multivariate analysis. The SNP (rs4073) in the IL8 gene is not associated with susceptibility to periodontitis in Brazilian individuals, even after controlling for covariates.

\section{Introduction}

$\mathbf{P}$ ERIOdOnTAL Diseases (PD), such as periodontitis and aggressive periodontitis, are characterized by a progressive gingival inflammatory response to the bacterial dental plaque, leading to destruction of periodontium and eventually tooth loss (Nibali et al., 2007). PD are multifactorial diseases whose manifestation and progression are determined by the response of the host to bacterial infection (Kinane and Hart, 2003). The host response is influenced by both environmental factors (e.g., smoking, oral hygiene, stress, and lifestyle) and genetic factors (Albandar, 2002). Periodontitis has been associated with systemic alterations such as low-grade inflammation (Slade et al., 2003), dyslipidemia (Katz et al., 2002), glucose intolerance (Nibali et al., 2007), endothelial dysfunction (Tonetti et al., 2007), cardiovascular disease (Scannapieco et al., 2003), and metabolic syndrome (D'Aiuto et al., 2008).

Interleukin-8 (IL-8) is a potent chemoattractant and activator of neutrophils in inflammatory regions (Bickel, 1993). In the periodontal tissue, neutrophils are the first line of defense against periodontopathic bacteria, and play an important role in pathogenesis of periodontitis (Van Dyke and Vaikuntam, 1994). The role of IL-8 in the pathological process of chronic PD has been previously investigated. Levels of the IL-8 protein found in the gingival crevicular fluid from patients with chronic PD were significantly higher than those in controls. Expression of the IL8 gene was detected in human periodontal ligament cells and gingival fibroblasts in culture after stimulation with lipopolysaccharides from periodontal pathogens, which could trigger infiltration of several inflammatory cells into the periodontal tissues (Tamura et al., 1992; Yamamoto et al., 2006). Consequently, strong inflammatory reactions can occur at local sites, resulting in the destruction of periodontal tissues (Okada and Murakami, 1998).

There has been a particular interest in investigating functional polymorphisms in candidate genes for association with disease. Functional single-nucleotide polymorphisms (SNPs) may cause phenotypic changes through multiple mechanisms. For example, they may change the sequence of a protein, or affect gene regulation, mRNA processing, and translation (Wang and Sadee, 2006). The SNP (rs4073) (reference sequence number from the NCBI's Entrez system) in the promoter region of the IL8 gene is thought to be functional because its A allele has been shown to be associated with higher IL-8 production after stimulation with lipopolysaccharide (Hull et al., 2000). It is worth mentioning that

${ }^{1}$ Department of Oral Diagnosis and Surgery; ${ }^{2}$ Department of Morphology, School of Dentistry at Araraquara; UNESP—São Paulo State University, Araraquara, São Paulo, Brazil. 
the SNP (rs4073) has previously been referred to by other identifiers, such as -251 (Hull et al., 2000) and -353 (Renzoni et al., 2000).

Several studies have demonstrated that SNPs in cytokine genes may influence the susceptibility to PD and their severity (Scarel-Caminaga et al., 2002, 2004; Moreira et al., 2007; Wagner et al., 2007). However, to the best of our knowledge, the SNP (rs4073) in the IL8 gene had never been studied in individuals with PD. Therefore, the aim of this study was to investigate whether or not this functional SNP in the IL8 gene is associated with susceptibility to periodontitis in Brazilian individuals.

\section{Materials and Methods}

\section{Selection of subjects}

This study involved individuals from the State of São Paulo in the southeastern region of Brazil. A total of 500 subjects, all having similar socioeconomic status, were recruited from the patient pool of the School of Dentistry at Araraquara, UNESP-São Paulo State University, between November 2004 and May 2007. The study was approved by the Committee for Ethical Affairs of the São Paulo State University (Protocol number 57/04). All volunteers were informed about the aims and methods of this study, and gave their written consent to participate.

All subjects were required to have at least 10 remaining teeth and be in good general health. The exclusion criteria were a need for antibiotic prophylaxis, chronic usage of antiinflammatory drugs, current pregnancy, ongoing orthodontic therapy, and a self-declared history of systemic or local disease influencing the immune system, diabetes mellitus, HIV infection, or immunosuppressive chemotherapy.

Diagnosis of periodontitis was established through patient medical and dental histories. Each subject was examined by one of two calibrated periodontists, who carried out the periodontal examinations throughout the study period. To eliminate interexaminer variability, the kappa statistic test was calculated. Agreement of parameters between the dentists was tested for seven volunteers before the dental examinations (weighted kappa statistics $=0.74$ ).

The following clinical signs and parameters were assessed at six sites around each tooth: probing pocket depth (PPD) and clinical attachment level (CAL, as the distance from the cement-enamel junction to the base of the periodontal pocket) measured to the nearest millimeter by a periodontal probe with Williams makings (Trinity-Campo, Mourão, Brazil), and bleeding on probing (BOP), registered as present or absent, as a percentage of the total number of sites. The subjects were categorized into two groups:

- Control group: subjects exhibiting no sites with CAL and PPD $\geq 3 \mathrm{~mm}$ and BOP.

- Periodontitis group: subjects exhibiting one or more sites with CAL and PPD $\geq 3 \mathrm{~mm}$ and BOP.

Information on smoking status was obtained using a selfreporting questionnaire. Smoking status was assessed and subjects were classified as a smoker or a nonsmoker, according to Kornman et al. (1997). Smokers were current smokers, and nonsmokers were subjects who had never smoked or who had not smoked within the last 5 years.

\section{Analysis of genetic polymorphism}

Buccal epithelial cells from the subjects were obtained using $3 \mathrm{~mL}$ of $3 \%$ glucose mouthwash for $2 \mathrm{~min}$. DNA was extracted with sequential phenol/chloroform/isoamyl alcohol (25:24:1) solution and precipitated with salt ethanol solution. To genotype individuals for the SNP (rs4073) in the IL8 gene, a sequence-specific primer polymerase chain reaction (SSP-PCR) was performed as previously described by Renzoni et al. (2000), using the following primers: IL8 F-5' GTGGAACTGATTTCTATGTGAA 3', IL8 R-5' CACAATTT GGTGAATTATCAAT/A 3', control DRB F-5' TGCCAAGTG GAGCACCCAA $3^{\prime}$, and control DRB R-5' GCATCTTGCTCT GTGCAGAT $3^{\prime}$. PCR amplification was confirmed using control primers for the $D R B$ gene, which encodes a type of class II protein of from the major histocompatibility complex.

PCR was carried out using $1 \times$ buffer $(\mathrm{pH} 8.4,20 \mathrm{mM}$ Tris$\mathrm{HCl}$, and $50 \mathrm{mM} \mathrm{KCl}$; Invitrogen, São Paulo, SP, Brazil), $0.2 \mathrm{mM}$ of each dNTP (GE Healthcare Life Sciences, Buckinghamshire, England), $0.2 \mu \mathrm{M}$ of each control primer (Invitrogen, Frederick, MD), $1.5 \mu \mathrm{M}$ of each allele-specific primer (Invitrogen, Frederick, MD), $1.5 \mathrm{mM} \mathrm{MgCl} 2,0.75 \mathrm{U}$ Platinum Taq DNA polymerase (Invitrogen, São Paulo, SP, Brazil), and $100 \mathrm{ng}$ of genomic DNA, with a final reaction volume of $13 \mu \mathrm{L}$. The cycling conditions were as follows: $1 \mathrm{~min}$ at $96^{\circ} \mathrm{C} ; 5$ cycles of $25 \mathrm{~s}$ at $96^{\circ} \mathrm{C}, 45 \mathrm{~s}$ at $70^{\circ} \mathrm{C}$, and $25 \mathrm{~s}$ at $72^{\circ} \mathrm{C}$; 21 cycles of $25 \mathrm{~s}$ at $96^{\circ} \mathrm{C}, 50 \mathrm{~s}$ at $65^{\circ} \mathrm{C}$, and $30 \mathrm{~s}$ at $72^{\circ} \mathrm{C}$; and 4 cycles of $30 \mathrm{~s}$ at $96^{\circ} \mathrm{C}, 60 \mathrm{~s}$ at $55^{\circ} \mathrm{C}$, and $90 \mathrm{~s}$ at $72^{\circ} \mathrm{C}$. The SSP-PCR products were analyzed by electrophoresis on a $10 \%$ polyacrylamide (USB, Cleveland, $\mathrm{OH}$ ) gel, which was stained by the rapid silver staining method (Sanguinetti et al., 1994).

\section{Statistical analysis}

The illustrative power calculations for periodontitis, for the estimation of the relevance of the $p$-values produced from this dataset, were performed using the methodology for discrete traits in case-control studies (Purcell et al., 2003). The parameters considered were similar to those used by Brett et al. (2005), including a chronic periodontitis prevalence of 0.06 (Dini and Castellanos, 1995). Associations between the SNP (rs4073) and certain characteristics of the subjects (age, sex, skin color, and smoking status) in the control and periodontitis groups were analyzed using the chi-squared test, followed by univariate and multivariate logistic regression modeling. Statistical analyses were performed using the SAS statistical package v.9 (SAS Institute, Cary, NC). The BioEstat statistical package v.4.0 (UFPA, Belém, Brazil) was used to calculate Hardy-Weinberg expectations. Differences were considered significant when $p<0.05$.

\section{Results}

The power calculations we performed showed that a sample size of 175 individuals would be required to ascertain a significant association between PD and the studied genetic polymorphisms, with an $\alpha$-value of 0.001 and a power of $95 \%$. Therefore, the number of subjects enrolled in this study is large enough to detect association with an acceptable level of confidence.

The characteristics of the Brazilian population investigated here are presented in Table 1 . Subjects were categorized 
Table 1. Characteristics of the Studied Groups

\begin{tabular}{|c|c|c|c|}
\hline & Control $(\mathrm{n}=224)$ & Periodontitis $(\mathrm{n}=276)$ & Total $(\mathrm{n}=500)$ \\
\hline Age (years), mean $( \pm)$ & $35.3( \pm 10.4)$ & $43.4( \pm 10.5)$ & $39.7( \pm 11.2)$ \\
\hline \multicolumn{4}{|l|}{$\operatorname{Sex} n(\%)$} \\
\hline Female & $134(59.8 \%)$ & $175(63.4 \%)$ & $309(61.8 \%)$ \\
\hline Male & $90(40.2 \%)$ & $101(36.6 \%)$ & $191(38.2 \%)$ \\
\hline \multicolumn{4}{|l|}{ Skin color $n(\%)$} \\
\hline Whites & $148(66.0 \%)$ & $142(51.4 \%)$ & $290(58.0 \%)$ \\
\hline Darker-skinned blacks & $25(11.2 \%)$ & $62(22.4 \%)$ & $87(17.4 \%)$ \\
\hline Lighter-skinned blacks & $45(20.0 \%)$ & $71(25.7 \%)$ & $116(23.2 \%)$ \\
\hline Yellow-skinned individuals & $6(2.8 \%)$ & $1(0.5 \%)$ & $7(1.4 \%)$ \\
\hline \multicolumn{4}{|l|}{ Smoking habits $n(\%)$} \\
\hline Nonsmokers & $204(91.0 \%)$ & $211(76.4 \%)$ & $415(83.0 \%)$ \\
\hline Smokers & $20(9.0 \%)$ & $65(23.6 \%)$ & $85(17.0 \%)$ \\
\hline
\end{tabular}

according to their skin color composition, as proposed by Peres et al. (2007), into whites (predominantly of European descent), darker-skinned blacks (predominantly of African descent), lighter-skinned blacks (mixed European, African, and Amerindian ancestry), and yellow-skinned individuals (Asian ancestry) (Table 1).

The SNP (rs4073) could be genotyped for $97.6 \%$ of the samples. Genotyping failed in four patients from the control group and eight patients from the periodontitis group (compare Tables 1 and 2), probably due to the high percentage of cytosines and guanines in this promoter region of the IL8 gene. Nevertheless, the SSP-PCR method was efficient for genotyping (Fig. 1), as the genotypes of $10 \%$ of the samples (selected at random) were confirmed by the restriction fragment length polymorphism method (Rovin et al., 2002). The observed genotype distribution was consistent with the assumption of the Hardy-Weinberg equilibrium in both the control $(p=0.106)$ and periodontitis $(p=0.136)$ groups.

Table 2 shows the results of univariate analysis for association between the age, sex, skin color, smoking status, and genotypic distributions of patients and periodontitis. Significant associations between age (OR ranging from 3.62 for age group 30-39 to 27.1 for age group 60-69), skin color $(\mathrm{OR}=1.69$ for lighter-skinned blacks; OR = 2.66 for darker-skinned blacks), and smoking status $(\mathrm{OR}=3.38)$ and periodontitis were observed; therefore, they were considered confounding factors. On the other hand, neither sex nor the SNP (rs4073) in the IL8 gene was found to be associated with periodontitis.

To more accurately evaluate the strength of any association and to eliminate the distortion caused by confounding effects, multivariate analysis was performed. All the confounding factors detected by the univariate analysis were also observed by the multivariate analysis (Table 2). Even

Table 2. Odds Ratios for Periodontitis by Characteristics of the Patients (INCLUding the GeNOTYPES OF THE SNP RS4073 IN THE IL8 GENE)

\begin{tabular}{|c|c|c|c|c|c|c|}
\hline \multicolumn{2}{|c|}{ Characteristics of patients } & \multirow{2}{*}{$\frac{\text { Control }}{220}$} & \multirow{2}{*}{$\frac{\text { Periodontitis }}{268}$} & \multirow[t]{2}{*}{$\begin{array}{l}\text { Univariate OR } \\
\quad(95 \% \mathrm{CI})\end{array}$} & \multirow[t]{2}{*}{$\begin{array}{l}\text { Multivariate OR } \\
\quad(95 \% \text { CI })\end{array}$} & \multirow[t]{2}{*}{$\mathrm{p}-$ Value $^{\mathrm{a}}$} \\
\hline Total & & & & & & \\
\hline \multirow[t]{6}{*}{ Age } & $20-29$ & $82(77.36)$ & $24(22.64)$ & Reference & Reference & $<0.01$ \\
\hline & $30-39$ & $66(46.48)$ & 76 (53.52) & $3.628(2.091-6.293)$ & 3.392 (1.874-6.141) & \\
\hline & $40-49$ & $53(33.97)$ & $103(66.03)$ & $6.262(3.603-10.884)$ & $6.601(3.643-11.959)$ & \\
\hline & $50-59$ & $15(25.42)$ & $44(74.58)$ & 9.364 (4.499-19.492) & $10.488(4.824-22.802)$ & \\
\hline & $60-69$ & $2(10.53)$ & 17 (89.47) & $27.134(5.876-125.305)$ & 41.215 (8.639-196.630) & \\
\hline & $>70$ & $2(33.33)$ & $4(66.67)$ & $6.385(1.105-36.874)$ & $8.212(1.354-49.803)$ & \\
\hline \multirow[t]{2}{*}{ Sex } & Male & $90(47.12)$ & $101(52.88)$ & Reference & Reference & 0.91 \\
\hline & Female & $134(43.36)$ & $175(56.64)$ & $1.160(0.804-1.672)$ & $1.051(0.687-1.608)$ & \\
\hline \multirow[t]{4}{*}{ Skin color } & Whites & $148(51.03)$ & $142(48.97)$ & Reference & Reference & $<0.01$ \\
\hline & $\begin{array}{l}\text { Darker-skinned } \\
\text { blacks }\end{array}$ & $25(28.73)$ & $62(71.27)$ & $2.665(1.584-4.485)$ & $2.820(1.585-5.020)$ & \\
\hline & $\begin{array}{l}\text { Lighter-skinned } \\
\text { blacks }\end{array}$ & $45(38.79)$ & $71(61.21)$ & $1.696(1.090-2.636)$ & $1.824(1.116-2.981)$ & \\
\hline & $\begin{array}{l}\text { Yellow-skinned } \\
\text { individuals }\end{array}$ & $6(85.71)$ & $1(14.29)$ & $0.179(0.021-1.507)$ & $0.362(0.036-3.673)$ & \\
\hline \multirow[t]{2}{*}{ Smoking habits } & Nonsmokers & $204(49.16)$ & $211(50.84)$ & Reference & Reference & $<0.01$ \\
\hline & Smokers & $20(23.53)$ & 65 (76.47) & $3.387(1.960-5.854)$ & $4.010(2.205-7.292)$ & \\
\hline \multirow[t]{3}{*}{ SNP rs4073 } & $\mathrm{AA}$ & $36(39.13)$ & $56(60.87)$ & $1.508(0.877-2.593)$ & 1.463 (0.789-2.712) & 0.48 \\
\hline & $\mathrm{AT}$ & $120(45.11)$ & 146 (54.89) & $1.180(0.775-1.796)$ & $1.191(0.732-1.939)$ & \\
\hline & TT & $64(49.23)$ & 66 (50.77) & Reference & Reference & \\
\hline
\end{tabular}

${ }^{a}$ Obtained from chi-squared test. 


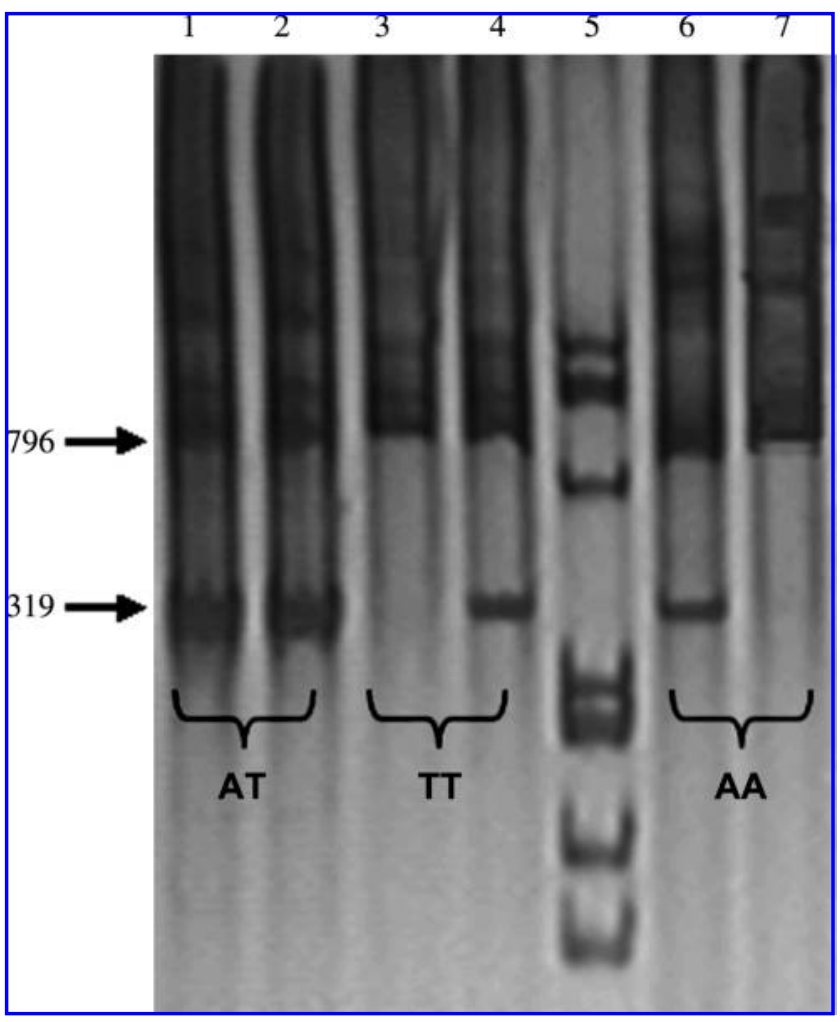

FIG. 1. Polyacrylamide gel $(10 \%)$ showing the results of sequence-specific primer (SSP)-PCR assay for analyzing the rs4073 polymorphism of the IL8 gene (319 bp). A control band is present in all lanes (796 bp). Two lanes were necessary to genotype a subject: in the first lane was applied the SSP-PCR to identify the A allele, and in the second lane to identify the T allele. Lane 5: PhiX174 HaeIII molecular weight marker.

though sex and genotypes of the SNP (rs4073) were not associated with periodontitis, we included them in the multivariate analysis, to adjust for any small confounding effects. The multiple logistic regression analysis also demonstrated that the association between the SNP (rs4073) and periodontitis is not significant, even after adjusting for covariates, including age, sex, skin color, and smoking status. Similarly, focusing on the alleles of the SNP (rs4073) and considering the $\mathrm{T}$ allele as a reference, the univariate and multivariate analyses showed that the A allele was not associated with periodontitis (OR $=1.199 \& 95 \%$ CI: $0.93-1.544$, and OR $=1.182 \&$ 95\% CI: 0.88-1.577, respectively).

\section{Discussion}

Genetic studies in several distinct populations have shown an association between the SNP (rs4073) in the IL8 gene and inflammatory diseases such as multiple sclerosis, bronchiolitis, and asthma (Hull et al., 2000; Heinzmann et al., 2004; Kamali-Sarvestani et al., 2006). Periodontitis is caused by a bacterial infection in which the periodontal tissues become inflamed and are destroyed by the action of the inflammatory process (Loos et al., 2005). In addition, considering the multifactorial nature of the periodontitis, there is strong supporting evidence that genes play a role in predisposition to PD. In a study with 117 adult twins, Michalowicz et al.
(2000) demonstrated that periodontitis had a heritability of approximately $50 \%$, which was unaltered after adjustments for behavioral variables, including smoking. Also, an increasing number of studies, conducted with different ethnic groups, have verified that there is a genetic susceptibility to periodontitis, mainly in genes of the host immune system, such as cytokines (Kornman et al., 1997; Scarel-Caminaga et al., 2002, 2004; Moreira et al., 2007; Wagner et al., 2007). However, in spite of the biological relevance of the IL8 gene and its participation in the inflammatory reaction of the periodontium (Tamura et al., 1992; Yamamoto et al., 2006), polymorphisms in this gene have never been investigated in association studies involving periodontitis.

In the present study, the functional SNP (rs4073) in the IL8 gene was not found to be associated with periodontitis. This result indicates that despite the fact that the A allele of the SNP (rs4073) has previously been shown to be associated with higher levels of IL-8 production, and associated with a higher risk of bronchiolitis, atrophic gastritis, and distal gastric cancer (Hull et al., 2000; Rovin et al., 2002; Puthothu et al., 2007), a negative association can be found for a different disease and in a different population. A possible explanation for the negative association of the SNP (rs4073) with periodontitis is that this SNP was analyzed alone. Some studies have shown lack of, or a slight disease association, when the SNP (rs4073) was analyzed alone, but they demonstrated significant association when the SNP (rs4073) was as part of a haplotype that included other nearby SNPs that were in linkage disequilibrium with the SNP (rs4073) (Rovin et al., 2002; Puthothu et al., 2007). Therefore, to analyze the genetic background of disease development, it seems more appropriate to investigate the cooperative influence of other polymorphisms in linkage disequilibrium with a functional SNP (Kinane and Hart, 2003).

To evaluate any potential confounding effects that could cause bias in this association study of periodontitis, important factors known to influence the pathogenesis of periodontitis were assessed by univariate and multivariate analysis. The univariate analysis showed that age, skin color, and smoking status were associated with periodontitis (Table 2). These findings were replicated in the multivariate analysis. Regarding age, an important risk factor for periodontitis, Grossi et al. (1995) observed an OR $=2.6$ (95\% CI: $1.75-3.83)$ for the age group 35-44 years and an $\mathrm{OR}=24.08$ (95\% CI: 15.93-36.29) for the age group 65-74 years, which are comparable to the results of the present study (Table 2) (Grossi et al., 1995). There is evidence that both the prevalence and severity of periodontitis increase with increasing age (Borrell and Papapanou, 2005). However, this age effect can conceivably represent the cumulative effect of prolonged exposure to other risk factors (Papapanou et al., 1991). Smoking has been established as an important risk factor for periodontitis (Genco, 1996; Kornman et al., 1997; Bergstrom, 2004; Kornman, 2005), which is in agreement with our study $\left(\mathrm{OR}_{\text {adjusted }}=4.0 ; 95 \%\right.$ CI: 2.205-7.292). Some studies have shown that smokers had significantly worse clinical symptoms of periodontitis than nonsmokers (Grossi et al., 1995; Okamoto et al., 2006).

In this study, skin color was found to be a confounding factor for periodontitis ( $\mathrm{OR}=1.69$ for lighter-skinned blacks; $\mathrm{OR}=2.66$ for darker-skinned blacks). The significance of the statistical values for these groups increased in the mul- 
tivariate analysis (Table 2). Similar results were found in another study enrolling Brazilian individuals in which lighterskinned black people and darker-skinned black people presented higher levels of PD when compared with white people $(\mathrm{OR}=1.5 \& 95 \%$ CI: $1.2-1.8$, and $\mathrm{OR}=1.6 \& 95 \%$ CI: 1.2-2.1, respectively), even after controlling for covariates like age and sex (Peres et al., 2007).

The main limitation of our study is the lack of information on severity of periodontitis. However, our data were originally produced in a survey context in which the aim of the study was to investigate whether the SNP (rs4073) is associated with periodontitis.

To our knowledge, this is the first report investigating an SNP in the IL8 gene in relation to periodontitis, in which we concluded that the SNP (rs4073) was not associated with susceptibility to periodontitis in Brazilian individuals, even after controlling for age, sex, skin color, and smoking status. The univariate and multivariate analyses showed that age, skin color, and smoking status were associated with periodontitis.

\section{Acknowledgments}

This study was supported by the Foundation for Research Support of the State of São Paulo-FAPESP Grants 2003/ 10424-0 and 2005/03231-7.

\section{Disclosure Statement}

No competing financial interests exist.

\section{References}

Albandar, J.M. (2002). Global risk factors and risk indicators for periodontal diseases. Periodontol 2000 29, 177-206.

Bergstrom, J. (2004). Tobacco smoking and chronic destructive periodontal disease. Odontology 92, 1-8.

Bickel, M. (1993). The role of interleukin-8 in inflammation and mechanisms of regulation. J Periodontol 64, 456-460.

Borrell, L.N., and Papapanou, P.N. (2005). Analytical epidemiology of periodontitis. J Clin Periodontol 32 Suppl 6, 132-158.

Brett, P.M., Zygogianni, P., Griffiths, G.S., Tomaz, M., Parkar, M., D'Aiuto, F., and Tonetti, M. (2005). Functional gene polymorphisms in aggressive and chronic periodontitis. J Dent Res 84, 1149-1153.

D'Aiuto, F., Sabbah, W., Netuveli, G., Donos, N., Hingorani, A.D., Deanfield, J., and Tsakos, G. (2008). Association of the Metabolic Syndrome with Severe Periodontitis in a Large U.S. Population-Based Survey. J Clin Endocrinol Metab 93, 39893994.

Dini, E.L., and Castellanos, R.A. (1995). CPITN: time and cost estimates for periodontal prevention and treatment procedures. Braz Dent J 6, 53-58.

Genco, R.J. (1996). Current view of risk factors for periodontal diseases. J Periodontol 67, 1041-1049.

Grossi, S.G., Genco, R.J., Machtei, E.E., Ho, A.W., Koch, G., Dunford, R., Zambon, J.J., and Hausmann, E. (1995). Assessment of risk for periodontal disease. II. Risk indicators for alveolar bone loss. I Periodontol 66, 23-29.

Heinzmann, A., Ahlert, I., Kurz, T., Berner, R., and Deichmann, K.A. (2004). Association study suggests opposite effects of polymorphisms within IL8 on bronchial asthma and respiratory syncytial virus bronchiolitis. J Allergy Clin Immunol 114, 671-676.
Hull, J., Thomson, A., and Kwiatkowski, D. (2000). Association of respiratory syncytial virus bronchiolitis with the interleukin 8 gene region in UK families. Thorax 55, 1023-1027.

Kamali-Sarvestani, E., Nikseresht, A.R., Aliparasti, M.R., and Vessal, M. (2006). IL-8 (-251 A/T) and CXCR2 (+1208 C/T) gene polymorphisms and risk of multiple sclerosis in Iranian patients. Neurosci Lett 404, 159-162.

Katz, J., Flugelman, M.Y., Goldberg, A., and Heft, M. (2002). Association between periodontal pockets and elevated cholesterol and low density lipoprotein cholesterol levels. I Periodontol 73, 494-500.

Kinane, D.F., and Hart, T.C. (2003). Genes and gene polymorphisms associated with periodontal disease. Crit Rev Oral Biol Med 14, 430-449.

Kornman, K.S. (2005). Diagnostic and prognostic tests for oral diseases: practical applications. J Dent Educ 69, 498-508.

Kornman, K.S., Crane, A., Wang, H.Y., di Giovine, F.S., Newman, M.G., Pirk, F.W., Wilson, T.G., Jr., Higginbottom, F.L., and Duff, G.W. (1997). The interleukin-1 genotype as a severity factor in adult periodontal disease. I Clin Periodontol 24, $72-77$.

Loos, B.G., John, R.P., and Laine, M.L. (2005). Identification of genetic risk factors for periodontitis and possible mechanisms of action. I Clin Periodontol 32 Suppl 6, 159-179.

Michalowicz, B.S., Diehl, S.R., Gunsolley, J.C., Sparks, B.S., Brooks, C.N., Koertge, T.E., Califano, J.V., Burmeister, J.A., and Schenkein, H.A. (2000). Evidence of a substantial genetic basis for risk of adult periodontitis. J Periodontol 71, 16991707.

Moreira, P.R., Costa, J.E., Gomez, R.S., Gollob, K.J., and Dutra, W.O. (2007). The IL1A (-889) gene polymorphism is associated with chronic periodontal disease in a sample of Brazilian individuals. J Periodontal Res 42, 23-30.

Nibali, L., D'Aiuto, F., Griffiths, G., Patel, K., Suvan, J., and Tonetti, M.S. (2007). Severe periodontitis is associated with systemic inflammation and a dysmetabolic status: a casecontrol study. J Clin Periodontol 34, 931-937.

Okada, H., and Murakami, S. (1998). Cytokine expression in periodontal health and disease. Crit Rev Oral Biol Med 9, 248 266.

Okamoto, Y., Tsuboi, S., Suzuki, S., Nakagaki, H., Ogura, Y., Maeda, K., and Tokudome, S. (2006). Effects of smoking and drinking habits on the incidence of periodontal disease and tooth loss among Japanese males: a 4-yr longitudinal study. J Periodontal Res 41, 560-566.

Papapanou, P.N., Lindhe, J., Sterrett, J.D., and Eneroth, L. (1991). Considerations on the contribution of ageing to loss of periodontal tissue support. J Clin Periodontol 18, 611615.

Peres, M.A., Antunes, J.L., Boing, A.F., Peres, K.G., and Bastos, J.L. (2007). Skin colour is associated with periodontal disease in Brazilian adults: a population-based oral health survey. J Clin Periodontol 34, 196-201.

Purcell, S., Cherny, S.S., and Sham, P.C. (2003). Genetic Power Calculator: design of linkage and association genetic mapping studies of complex traits. Bioinformatics 19, 149-150.

Puthothu, B., Krueger, M., Forster, J., Heinze, J., Weckmann, M., and Heinzmann, A. (2007). Interleukin (IL)-18 polymorphism $133 \mathrm{C} / \mathrm{G}$ is associated with severe respiratory syncytial virus infection. Pediatr Infect Dis J 26, 1094-1098.

Renzoni, E., Lympany, P., Sestini, P., Pantelidis, P., Wells, A., Black, C., Welsh, K., Bunn, C., Knight, C., Foley, P., and du Bois, R.M. (2000). Distribution of novel polymorphisms of the interleukin- 8 and CXC receptor 1 and 2 genes in systemic 
sclerosis and cryptogenic fibrosing alveolitis. Arthritis Rheum 43, 1633-1640.

Rovin, B.H., Lu, L., and Zhang, X. (2002). A novel interleukin-8 polymorphism is associated with severe systemic lupus erythematosus nephritis. Kidney Int 62, 261-265.

Sanguinetti, C.J., Dias Neto, E., and Simpson, A.J. (1994). Rapid silver staining and recovery of PCR products separated on polyacrylamide gels. Biotechniques 17, 914-921.

Scannapieco, F.A., Bush, R.B., and Paju, S. (2003). Associations between periodontal disease and risk for atherosclerosis, cardiovascular disease, and stroke. A systematic review. Ann Periodontol 8, 38-53.

Scarel-Caminaga, R.M., Trevilatto, P.C., Souza, A.P., Brito, R.B., Camargo, L.E., and Line, S.R. (2004). Interleukin 10 gene promoter polymorphisms are associated with chronic periodontitis. J Clin Periodontol 31, 443-448.

Scarel-Caminaga, R.M., Trevilatto, P.C., Souza, A.P., Brito, R.B., and Line, S.R. (2002). Investigation of an IL-2 polymorphism in patients with different levels of chronic periodontitis. J Clin Periodontol 29, 587-591.

Slade, G.D., Ghezzi, E.M., Heiss, G., Beck, J.D., Riche, E., and Offenbacher, S. (2003). Relationship between periodontal disease and C-reactive protein among adults in the Atherosclerosis Risk in Communities study. Arch Intern Med 163, 1172-1179.

Tamura, M., Tokuda, M., Nagaoka, S., and Takada, H. (1992). Lipopolysaccharides of Bacteroides intermedius (Prevotella intermedia) and Bacteroides (Porphyromonas) gingivalis induce interleukin-8 gene expression in human gingival fibroblast cultures. Infect Immun 60, 4932-4937.

Tonetti, M.S., D'Aiuto, F., Nibali, L., Donald, A., Storry, C., Parkar, M., Suvan, J., Hingorani, A.D., Vallance, P., and
Deanfield, J. (2007). Treatment of periodontitis and endothelial function. N Engl J Med 356, 911-920.

Van Dyke, T.E., and Vaikuntam, J. (1994). Neutrophil function and dysfunction in periodontal disease. Curr Opin Periodontol 19-27.

Wagner, J., Kaminski, W.E., Aslanidis, C., Moder, D., Hiller, K.A., Christgau, M., Schmitz, G., and Schmalz, G. (2007). Prevalence of OPG and IL-1 gene polymorphisms in chronic periodontitis. J Clin Periodontol 34, 823-827.

Wang, D., and Sadee, W. (2006). Searching for polymorphisms that affect gene expression and mRNA processing: example ABCB1 (MDR1). AAPS J 8, E515-E520.

Yamamoto, T., Kita, M., Oseko, F., Nakamura, T., Imanishi, J., and Kanamura, N. (2006). Cytokine production in human periodontal ligament cells stimulated with Porphyromonas gingivalis. I Periodontal Res 41, 554-559.

Address reprint requests to: Raquel M. Scarel-Caminaga, Ph.D.

Department of Morphology School of Dentistry at Araraquara UNESP-São Paulo State University, CP. 331 Araraquara CEP 14801-903 São Paulo Brazil

E-mail: raquel@foar.unesp.br

Received for publication September 15, 2008; received in revised form December 22, 2008; accepted December 22, 2008. 


\section{This article has been cited by:}

1. L. S. Finoti, S. C. T. Corbi, G. Anovazzi, S. R. L. Teixeira, J. P. Steffens, R. Secolin, Y. J. Kim, S. R. P. Orrico, J. A. Cirelli, M. P. A. Mayer, R. M. Scarel-Caminaga. 2013. Association between IL8 haplotypes and pathogen levels in chronic periodontitis. European Journal of Clinical Microbiology \& Infectious Diseases . [CrossRef]

2. Denise Carleto Andia, Ariadne Letra, Renato Corrêa Viana Casarin, Marcio Zaffalon Casati, Sergio Roberto Peres Line, Ana Paula de Souza. 2013. Genetic analysis of the IL8 gene polymorphism (rs4073) in generalized aggressive periodontitis. Archives of Oral Biology 58:2, 211-217. [CrossRef]

3. Sâmia C.T. Corbi, Giovana Anovazzi, Lívia S. Finoti, Yeon J. Kim, Marisa V. Capela, Rodrigo Secolin, Andrea M. Marcaccini, Raquel F. Gerlach, Silvana R.P. Orrico, Joni A. Cirelli, Raquel M. Scarel-Caminaga. 2012. Haplotypes of susceptibility to chronic periodontitis in the Interleukin 8 gene do not influence protein level in the gingival crevicular fluid. Archives of Oral Biology 57:10, 1355-1361. [CrossRef]

4. Guangyue Li, Yuan Yue, Ye Tian, Jin-le Li, Min Wang, Hao Liang, Peixi Liao, Wings T.Y. Loo, Mary N.B. Cheung, Louis W.C. Chow. 2012. Association of matrix metalloproteinase (MMP)-1, 3, 9, interleukin (IL)-2, 8 and cyclooxygenase (COX)-2 gene polymorphisms with chronic periodontitis in a Chinese population. Cytokine . [CrossRef]

5. Marja L. Laine, Wim Crielaard, Bruno G. Loos. 2012. Genetic susceptibility to periodontitis. Periodontology 2000 58:1, 37-68. [CrossRef]

6. Scott R. Diehl, Chih-Hung Chou, Fengshen Kuo, Ching-Yu HuangGenetic Factors and Periodontal Disease 271-284. [CrossRef]

7. Denise C. Andia, Naila F. P. de Oliveira, Ariadne M. Letra, Francisco H. Nociti, Sergio R. P. Line, Ana P. de Souza. 2011. Interleukin-8 Gene Promoter Polymorphism (rs4073) May Contribute to Chronic Periodontitis. Journal of Periodontology 82:6, 893-899. [CrossRef]

8. Raquel M. Scarel-Caminaga, Yeon J. Kim, Aline C. Viana, Karen M. C. Curtis, Sâmia C. T. Corbi, Patrícia M. Sogumo, Silvana R. P. Orrico, Joni A. Cirelli. 2011. Haplotypes in the Interleukin 8 Gene and Their Association with Chronic Periodontitis Susceptibility. Biochemical Genetics 49:5-6, 292-302. [CrossRef]

9. M. M. Grant. 2011. What do 'omic technologies have to offer periodontal clinical practice in the future?. Journal of Periodontal Research no-no. [CrossRef]

10. Yeon Jung Kim, Aline Cavalcante Viana, Karen Maria C. Curtis, Silvana Regina Perez Orrico, Joni Augusto Cirelli, Celso Teixeira Mendes-Junior, Raquel Mantuaneli Scarel-Caminaga. 2010. Association of haplotypes in the IL8 gene with susceptibility to chronic periodontitis in a Brazilian population. Clinica Chimica Acta 411:17-18, 1264-1268. [CrossRef]

11. Aline C. Viana, Yeon J. Kim, Karen M.C. Curtis, Rivelto Renzi, Silvana R.P. Orrico, Joni A. Cirelli, Raquel M. Scarel-Caminaga. 2010. Association of Haplotypes in the CXCR2 Gene with Periodontitis in a Brazilian Population. DNA and Cell Biology 29:4, 191-200. [Abstract] [Full Text HTML] [Full Text PDF] [Full Text PDF with Links]

12. Giovana Anovazzi, Yeon J. Kim, Aline C. Viana, Karen M.C. Curtis, Silvana R.P. Orrico, Joni A. Cirelli, Raquel M. ScarelCaminaga. 2010. Polymorphisms and Haplotypes in the Interleukin-4 Gene are Associated With Chronic Periodontitis in a Brazilian Population. Journal of Periodontology 81:3, 392-402. [CrossRef] 